\title{
Giant cell arteritis presenting as a stroke in the internal carotid artery territory: a case-based review
}

\author{
Edoardo Conticini ID , Paolo Falsetti ID , Marco Bardelli, Luca Cantarini ID , Bruno Frediani \\ Department of Medicine, Surgery and Neurosciences, Rheumatology Unit, University of Siena, Italy
}

\begin{abstract}
Giant cell arteritis (GCA) is a large-vessel vasculitis, typically affecting the aorta and its branches. The involvement of vertebral and internal carotid arteries occurs in a limited number of cases, and stroke as a presenting symptom of GCA is extremely unusual: this subset of the disease has a poor prognosis and rarely responds to immunosuppression.

We report the case of a 70-year-old woman, who presented to the Emergency Department for ischemic stroke, which appeared to be the first and only symptom of GCA. The prompt administration of steroids and tocilizumab (TCZ) led to clinical and radiological resolution, with no residual disability at 6-month follow-up.

Our case-based review, highlighting the rarity of a large vessel vasculitis presenting only with a cerebrovascular accident, provides new evidence for the efficacy of TCZ even in more unusual varieties of GCA: in these cases, TCZ should be immediately prescribed, in order to prevent mortality and severe long-term morbidity.
\end{abstract}

Key words: stroke, vasculitis, ultrasonography, giant cell arteritis.

\section{Introduction}

Giant cell arteritis (GCA) is a large-vessel vasculitis involving the aorta and its major branches: in particular, the involvement of the temporal artery (TA), occurring in one third of the patients, may lead to irreversible blindness. It typically affects elderly people, and stroke is an extremely unusual presenting symptom, with poor prognosis and scarce response to therapy.

\section{Methods}

We reviewed the existing published literature regarding cases of GCA presenting with stroke or any other cerebral ischemic event. An extensive search was conducted via PubMed for papers written in English language using the following items/key words: "giant cell arteritis" combined with "stroke", "brain" or "cerebral".

Due to the lack of prospective studies, paucity of data and disease rarity, case reports and case series were also considered. Relevant references cited in the selected papers were searched manually and included in the review.

\section{Results}

\section{Case description}

In this regard, we report the case of a 70-year-old woman, whose previous medical history was unremarkable, who presented to the Emergency Department for headache and sudden left arm paresis.

Blood examination revealed C-reactive protein (CRP - $7.7 \mathrm{mg} / \mathrm{dl}$ ) and erythrocyte sedimentation rate (ESR - $36 \mathrm{~mm} / \mathrm{h}$ ) elevation, but no further alterations.

A non-contrast computed tomography (CT) was negative for acute brain hemorrhage, while magnetic resonance imaging (MRI) was consistent for subacute right frontal-temporal ischemic lesion.

Further imaging techniques (head and neck angio$\mathrm{CT}$, angio-MRI and cerebral angiography) revealed right internal carotid artery (ICA) severe occlusion (Fig. 1) and dissection after its origin. Both common carotid arteries (CCA) and left subclavian (SA) and vertebral arteries (VA) appeared thickened and narrowed, leading to a suspicion of GCA. 


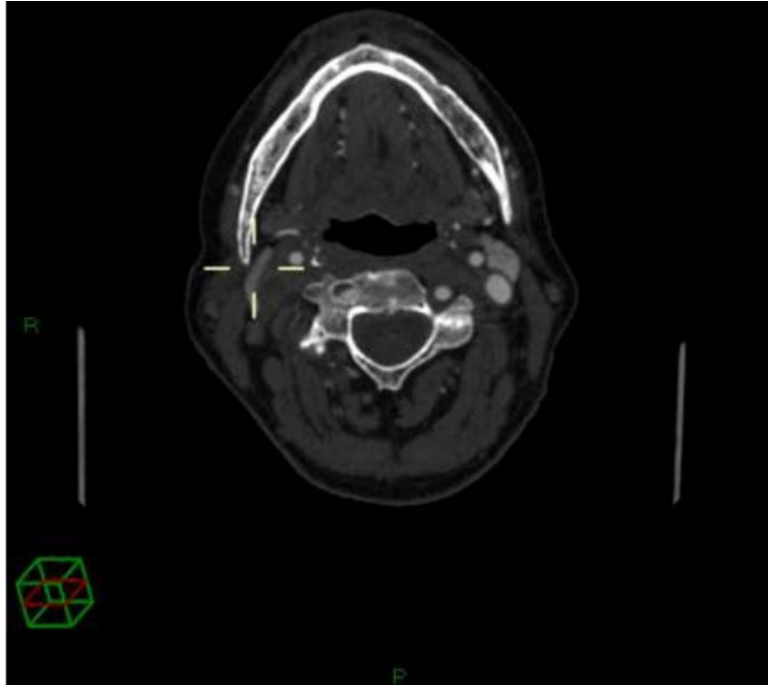

Fig. 1. Severe occlusion of right internal carotid artery.

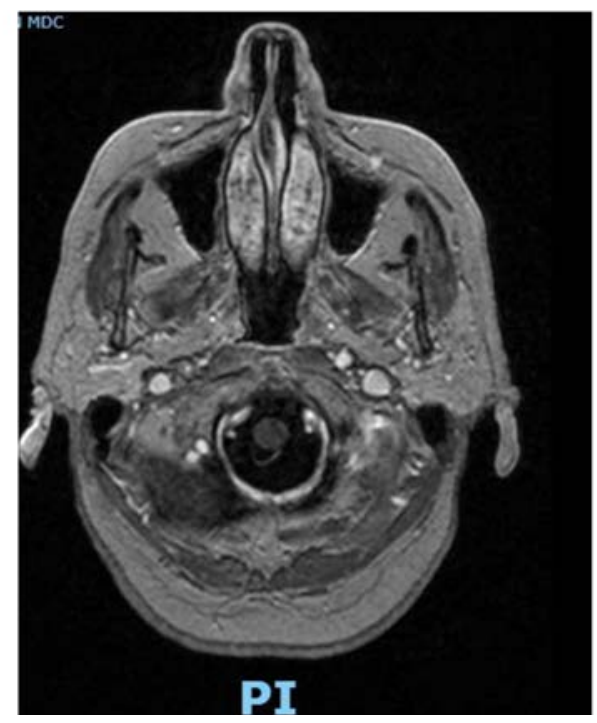

Fig. 2. Partial recanalization of right internal carotid artery at follow-up magnetic resonance imaging.

Color-doppler ultrasonography (CDUS) was then performed and showed a concentric "halo" sign around the VA, SA and CCA, with no flow in the territory of the right ICA. No significant atherosclerotic plaques were detected. No pathological findings were reported for TA, so a biopsy was not performed, while ${ }^{18} \mathrm{FDG}$-positron emission tomography-computed tomography revealed FDG uptake in the territory of the sopra-aortic trunks and aortic arch.

Intravenous methylprednisolone $500 \mathrm{mg} /$ day was promptly administered, followed by oral prednisone $1 \mathrm{mg} / \mathrm{kg}$, slowly tapered, and tocilizumab $162 \mathrm{mg}$ weekly. Antiplatelet therapy was added immediately after patient discharge.
After six months of therapy, the patient was fully asymptomatic and inflammatory markers fully normalized (CRP - $0.08 \mathrm{mg} / \mathrm{dl}, \mathrm{ESR}-6 \mathrm{~mm} / \mathrm{h}$ ), while complete blood count, serum cholesterol, liver and kidney function tests and urinalysis displayed no significant alterations.

Moreover, MRI revealed partial recanalization of the ICA and normal findings of the other vessels (Fig. 2), and PET and CDUS findings were fully normalized.

\section{Discussion}

Depending on the arteries primarily involved, the clinical presentation of GCA may vary from constitutional symptoms to amaurosis fugax, jaw, arm or leg claudication, headache, scalp tenderness and eventually stroke. The latter, which is directly related to the inflammatory involvement of the CA, VA, and more seldom intracranial arteries [1, 2], is an uncommon manifestation of GCA, particularly feared due to the poor prognosis and severe morbidity.

The prevalence of stroke and other cerebrovascular accidents (CVAs) in patients affected by GCA is generally low and ranges from $1.5 \%$ [3] to 16\% [4], as reported in several case series and retrospective studies coming from monocentric or multicentric databases.

The different design of these studies, as well as the notable variability of the population included, may explain such a difference in terms of prevalence; as a matter of fact, some studies included only patients who suffered from stroke within the first month after GCA diagnosis $[5,6]$, while other authors also considered CVAs during long-term follow-up [7].

However, only a few studies have assessed the prevalence of GCA among patients affected by ischemic stroke; a recent paper found that 4 out of 2417 patients admitted to a Spanish hospital for stroke had a concomitant GCA [8].

A cerebrovascular accident as the only presenting symptom of GCA is an even more unusual finding [2, 5, 9-12] (Table I).

In 1988, Caselli et al. [13] reported transient ischemic attacks (TIA) or stroke in 12 out of 166 patients (7.6\%) with biopsy-proven GCA, but only 5 suffered from stroke within the first days after the diagnosis of GCA.

Similarly, in only 2 out of 4 patients from the cohort by Samson et al. [14] was stroke simultaneous with GCA diagnosis, while in a more recent French multicentric retrospective study [4], stroke or TIA was found in 18 out of $129(16 \%)$ patients affected by GCA, but only 7 of them suffered from an ischemic event at diagnosis, the other 11 occurring within a year after GCA diagnosis.

Notably, all patients who suffered from CVA as the presenting symptom of GCA had relevant cardiovascular risk factors: despite conflicting data in the literature, and 
Table I. Previously reported cases of stroke as the presenting and only sign of giant cell arteritis, compared with our patient; papers reporting cases of multi-infarct dementia were excluded

\begin{tabular}{|c|c|c|c|c|c|c|}
\hline Authors & $\begin{array}{l}\text { Patients } \\
\text { (n) }\end{array}$ & Age/gender & $\begin{array}{l}\text { Comorbidities or } \\
\text { cardiovascular risk } \\
\text { factors }\end{array}$ & $\begin{array}{l}\text { Vessels } \\
\text { affected }\end{array}$ & Therapy & Outcome \\
\hline $\begin{array}{l}\text { Alsolaimani } \\
\text { et al. [2] }\end{array}$ & 1 & $82 /$ male & Yes & VA & GCs, CFX, MTX & Partial recovery \\
\hline Pariente et al. [4] & 7 & Not reported & Not reported & Not reported & Not reported & Not reported \\
\hline $\begin{array}{l}\text { Salvarani } \\
\text { et al. [5] }\end{array}$ & 5 & Not reported & Not reported & VA (5) & Not reported & Not reported \\
\hline $\begin{array}{l}\text { Larivière } \\
\text { et al. [9] }\end{array}$ & 8 & $\begin{array}{l}\text { 61/female } \\
\text { 59/male } \\
\text { 73/male } \\
\text { 72/female } \\
\text { 71/male } \\
66 / \text { male } \\
\text { 82/male } \\
\text { 77/male }\end{array}$ & $\begin{array}{l}\text { Yes } \\
\text { Yes } \\
\text { Yes } \\
\text { Yes } \\
\text { Yes } \\
\text { Yes } \\
\text { Yes } \\
\text { Yes }\end{array}$ & $\begin{array}{l}\text { VA, CA } \\
\text { VA, CA } \\
\text { VA } \\
\text { VA } \\
\text { VA } \\
\text { VA, CA } \\
\text { VA, CA } \\
\text { VA }\end{array}$ & $\begin{array}{c}\text { GCs, RTX, AZA, } \\
\text { TCZ, MMF, MTX } \\
\text { GCs, CFX, AZA } \\
\text { GCs } \\
\text { GCs } \\
\text { GCs } \\
\text { GCs } \\
\text { GCs } \\
\text { GCs, AZA, CFX }\end{array}$ & $\begin{array}{l}\text { Dementia } \\
\text { Recovery } \\
\text { Death } \\
\text { Recovery } \\
\text { Recovery } \\
\text { Recovery } \\
\text { Recovery } \\
\text { Partial recovery }\end{array}$ \\
\hline $\begin{array}{l}\text { Howard } \\
\text { et al. [10] }\end{array}$ & 1 & 65/female & Yes & ICA & None & Death \\
\hline $\begin{array}{l}\text { Solans-Laqué } \\
\text { et al. [11] }\end{array}$ & 1 & $85 /$ female & Yes & Not reported & GCs & Dementia \\
\hline $\begin{array}{l}\text { Elhfnawy } \\
\text { et al. [12] }\end{array}$ & 1 & 67/male & Yes & VA & GCs, AZA & Relapse \\
\hline $\begin{array}{l}\text { Samson } \\
\text { et al. [14] }\end{array}$ & 2 & $\begin{array}{l}\text { 80/male } \\
89 / \text { male }\end{array}$ & $\begin{array}{l}\text { Yes } \\
\text { Yes }\end{array}$ & $\begin{array}{l}\text { Not reported } \\
\text { Not reported }\end{array}$ & $\begin{array}{l}\text { GCs } \\
\text { GCs }\end{array}$ & $\begin{array}{c}\text { Death } \\
\text { Partial recovery }\end{array}$ \\
\hline Nesher et al. [15] & 13 & Not reported & Not reported & VA (6) & Not reported & Not reported \\
\hline Our patient & 1 & 70/female & No & ICA & GCs, TCZ & Full recovery \\
\hline
\end{tabular}

AZA - azathioprine, CA - carotid arteries, CFX - cyclophosphamide, GCS-glucocorticoids, MMF-mycophenolate mofetil, RTX - rituximab, $T C Z$ - tocilizumab, VA - vertebral arteries.

also comprising patients who had stroke after the diagnosis of GCA, male gender, previous transient cerebroophthalmic ischemic episodes [15], smoking history [6], coronary heart disease and hypertension [5] seem to be associated with the development of CVAs, while further CVAs during follow-up seem to be predicted by an ischemic event at baseline [15].

Conversely, low markers of inflammation at baseline $[4,5,16]$ and the presence of systemic symptoms $[5,15]$ negatively predict the onset of strokes or TIA.

On the other hand, other authors did not find statistically significant differences in terms of clinical, laboratory and epidemiological data between the patients who suffered from CVAs and the other ones [17].

Another interesting finding from our literature review is that almost all patients included (Table I) had a stroke in the CA territory, while only a minority had a stroke in the vertebra-basilar territory. This is not surprising, as it is well known that CVAs during GCA tend to predominantly affect the vertebra-basilar territory, while the CA is usually spared [18]: the posterior circle was involved in percentages ranging from $46 \%$ to $100 \%$ of the patients from retrospective studies on three French $[9,14,16]$, two Spanish [6, 8], one Italian [5] and one Israeli [15] cohorts.

Remarkably, concomitant occlusion of both vessels occurs in a very limited number of cases [8], and to the best of our knowledge only one GCA patient presented with a stroke in both the CA and VA territory [9].

Intracranial vessels are rarely affected, presumably due to the reduced expression of elastic tissue and vasa vasorum after dura mater perforation: indeed, GCA tends to affect arteries with elastic tissue within their wall, in which the vasa vasorum represent the door for inflammatory cells [19].

In our literature review, we did not find any case of stroke in the intracranial vessel as the presenting symptom of GCA.

The outcome is usually poor, with a significant reduction of both survival and remission-free survival, 
despite high dosage of steroids $[4,20]$ and immunosuppressants, such as cyclophosphamide (CFX) [21], methotrexate (MTX) [8], rituximab (RTX) [9] and, more recently, tocilizumab (TCZ) [9, 22, 23].

Endovascular dilatation of stenotic arteries has been successfully proposed in 4 patients unresponsive to high dosages of steroids [24], but it is presumably less effective in reducing inflammation, potentially leading to further occlusions. Moreover, stenosis may worsen despite the normalization of markers of inflammation [8].

De Boysson et al. [16], in their retrospective study of 40 patients affected by GCA-associated stroke, reported a mortality rate of $28 \%$, often (63\%) within the first 5 days, and a disability rate of $52 \%$ among the survivors, with frequent relapses. An even worse outcome is reported among the few cases of intracranial GCA reported in the literature (7 out of 9 patients deceased) [1] and a 100\% lethality was observed by Samson et al. [14] in those patients in whom stroke was the presenting symptom, despite high dosage of steroids. Long-term complications are frequent and may lead to severe morbidity and mortality [9, 14, 25].

Relapses may occur in a non-negligible number of cases: further CVAs were assessed in $28 \%$ of patients from the French multicentric study by de Boysson [16], despite concomitant immunosuppression. Conversely, no further relapses and an overall good outcome were noted in all 6 patients from the case series by Zenone et al. [17].

Cerebrovascular accidents are an uncommon, serious, probably underdiagnosed and difficult-to-treat complication of GCA, and, in a low percentage of cases, may represent the only symptom at onset. Differential diagnosis with thromboembolic occlusion is challenging, particularly in the elderly.

Anyway, the presence of constitutional symptoms, elevated inflammatory markers and the absence of cardiovascular risk factors as well as the predilection for the posterior circle, less involved by atherosclerotic plaques, should lead to the suspicion of GCA.

Our case is remarkable: stroke was the first sign of GCA and the occlusion occurred in the territory of the CA, while GCA predominantly affects the VA [6]; secondly, our patient did not suffer from any risk factors related to the development of CVA in GCA [5, 6]; finally, despite the dramatic onset, she had a brilliant response to TCZ, survived and did not suffer from any significant disability or any further CVAs, which are a common complication in GCA patients suffering from ischemic events at baseline [15].

To our knowledge, ours represents the first case of GCA-related stroke fully resolved after 6 months of therapy with TCZ, with an imaging-proved improvement of vessel occlusion.
Only a few papers have previously reported the use of anti-interleukin 6 drugs in this condition [9, 22, 23]. In all of them, TCZ was administered several months after diagnosis, after conventional and biological immunosuppressants (MTX, CFX, RTX and azathioprine), and in all 3 cases TCZ was unable to control disease activity, which led to the death of one patient and to severe disability of the other 2, who suffered from further relapses.

Our case highlights the efficacy of TCZ in inducing remission in GCA, also in such an unusual presentation. Despite the scarcity of data about this condition, it should be stressed that classical immunosuppressants are often unable to prevent death and disability, while TCZ's efficacy in "classical" GCA has been proven in several studies [26]. Finally, in the presented patient, there was a dramatic improvement of imaging findings in MRI, PET and CDUS.

\section{Conclusions}

The presented case and available data confirmed the effectiveness of TCZ in GCA by use of imaging methods, as well as the need for instrumental monitoring $[8,27]$, particularly in this condition, burdened by frequent relapses despite the normalization of inflammatory markers. Tocilizumab may be administered within the very first days after diagnosis as a first line therapy.

The authors declare no conflict of interest.

\section{References}

1. Salvarani C, Giannini C, Miller DV, Hunder G. Giant cell arteritis: involvement of intracranial arteries. Arthritis Rheum 2006; 55 : 985-989, DOI: 10.1002/art.22359.

2. Alsolaimani RS, Bhavsar SV, Khalidi NA, et al. Severe intracranial involvement in giant cell arteritis: 5 cases and literature review. J Rheumatol 2016; 43: 648-656, DOI: 10.3899/jrheum. 150143.

3. Cid MC, Font C, Oristrell J, et al. Association between strong inflammatory response and low risk of developing visual loss and other cranial ischemic complications in giant cell (temporal) arteritis. Arthritis Rheum 1998; 41: 26-32, DOI: 10.1002/1529-0131(199801)41:1<26::AID-ART4>3.0.CO;2-0.

4. Pariente A, Guédon A, Alamowitch $S$, et al. Ischemic stroke in giant-cell arteritis: French retrospective study. J Autoimmun 2019; 99: 48-51, DOI: 10.1016/j.jaut.2019.01.009.

5. Salvarani C, Della Bella C, Cimino L, et al. Risk factors for severe cranial ischaemic events in an Italian population-based cohort of patients with giant cell arteritis. Rheumatology (Oxford) 2009; 48: 250-253, DOI: 10.1093/rheumatology/ken465.

6. Gonzalez-Gay MA, Vazquez-Rodriguez TR, Gomez-Acebo I, et al. Strokes at time of disease diagnosis in a series of 287 patients with biopsy-proven giant cell arteritis. Medicine (Baltimore) 2009; 88: 227-235, DOI: 10.1097/MD.0b013e3181af4518. 
7. Lee MS, Smith SD, Galor A, Hoffman GS. Antiplatelet and anticoagulant therapy in patients with giant cell arteritis. Arthritis Rheum 2006; 54: 3306-3309, DOI: 10.1002/art.22141.

8. Guisado-Alonso D, Edo MC, Estrada Alarcón PV, et al. Progression of large vessel disease in patients with giant cell arteritis-associated ischemic stroke: the role of vascular imaging: a case series. J Clin Rheumatol 2020, DOI: 10.1097/RHU. 0000000000001498 [Online ahead of print].

9. Larivière D, Sacre K, Klein I, et al. Extra- and intracranial cerebral vasculitis in giant cell arteritis: an observational study. Medicine (Baltimore) 2014; 93: e265, DOI: 10.1097/ MD.0000000000000265.

10. Howard GF 3rd, Ho SU, Kim KS, Wallach J. Bilateral carotid artery occlusion resulting from giant cell arteritis. Ann Neurol 1984; 15: 204-207, DOI: 10.1002/ana.410150216.

11. Solans-Laqué R, Bosch-Gil JA, Molina-Catenario CA, et al. Stroke and multi-infarct dementia as presenting symptoms of giant cell arteritis: report of 7 cases and review of the literature. Medicine (Baltimore) 2008; 87: 335-344, DOI: 10.1097/ MD.0b013e3181908e96.

12. Elhfnawy AM, Bieber M, Schliesser M, Kraft P. Atypical presentation of giant cell arteritis in a patient with vertebrobasilar stroke: A case report. Medicine (Baltimore) 2019; 98: e16737, DOI: 10.1097/MD.0000000000016737.

13. Caselli RJ, Hunder GG, Whisnant JP. Neurologic disease in biopsy-proven giant cell (temporal) arteritis. Neurology 1988; 38: 352-359, DOI: 10.1212/wnl.38.3.352.

14. Samson M, Jacquin A, Audia S, et al. Stroke associated with giant cell arteritis: a population-based study. J Neurol Neurosurg Psychiatry 2015; 86: 216-221, DOI: 10.1136/jnnp-2014-307614.

15. Nesher G, Berkun Y, Mates M, et al. Risk factors for cranial ischemic complications in giant cell arteritis. Medicine (Baltimore) 2004; 83: 114-122, DOI: 10.1097/01.md.0000119761.27564.c9.

16. de Boysson $\mathrm{H}$, Liozon $\mathrm{E}$, Larivière $\mathrm{D}$, et al. Giant cell arteritis-related stroke: a retrospective multicenter case-control study. J Rheumatol 2017; 44: 297-303, DOI: 10.3899/jrheum.161033.

17. Zenone T, Puget M. Characteristics of cerebrovascular accidents at time of diagnosis in a series of 98 patients with giant cell arteritis. Rheumatol Int 2013; 33: 3017-3023, DOI: 10.1007/ s00296-013-2814-0.

18. Cull RE. Internal carotid artery occlusion caused by giant cell arteritis. J Neurol Neurosurg Psychiatry 1979; 42: 1066-1067, DOI: 10.1136/jnnp.42.11.1066.

19. Wilkinson IM, Russell RW. Arteries of the head and neck in giant cell arteritis. A pathological study to show the pattern of arterial involvement. Arch Neurol 1972; 27: 378-391, DOI: 10.1001/archneur.1972.00490170010003.

20. Healy S, Simpson M, Kitchen WJ, et al. Steroid refractory giant cell arteritis with bilateral vertebral artery occlusion and middle cerebellar peduncle infarction. J R Coll Physicians Edinb 2019; 49: 118-121, DOI: 10.4997/JRCPE.2019.206.

21. Chomlak DR, Ghazanfari F, Datta M. Case study: giant cell arteritis with vertebral artery stenosis. Clin Med Insights Arthritis Musculoskelet Disord 2016; 9: 103-107, DOI: 10.4137/CMAMD. $\mathrm{S} 38143$

22. Cox BC, Fulgham JR, Klaas JP. Recurrent stroke in giant cell arteritis despite immunotherapy. Neurologist 2019; 24: 139-141, DOI: 10.1097/NRL.0000000000000237.

23. Oerding C, Kaden I, Wohlfarth K. Isolated bilateral internal carotid artery stenosis and recurrent ischemic strokes in a patient with suspected giant cell arteritis. Case Rep Neurol 2020; 12: 84-91, DOI: 10.1159/000504018.

24. Simonsen CZ, Speiser L, Hansen IT, et al. Endovascular treatment of intracerebral giant cell arteritis. Front Neurol 2020; 11 : 287, DOI: 10.3389/fneur.2020.00287.

25. Vassallo C, Ceci Bonello E, Borg A. Giant cell arteritis presenting as multifocal cerebral infarcts. BMJ Case Rep 2020; 13: e236823, DOI: $10.1136 /$ bcr-2020-236823.

26. Stone JH, Tuckwell K, Dimonaco S, et al. Trial of tocilizumab in giant-cell arteritis. N Engl J Med 2017; 377: 317-328, DOI: 10.1056/NEJMoa1613849.

27. Conticini E, Sota J, Falsetti P, et al. The Role of multimodality imaging in monitoring disease activity and therapeutic response to tocilizumab in giant cell arteritis. Mediators Inflamm 2020; 2020: 3203241, DOI: 10.1155/2020/3203241. 